\title{
Countermeasures and Analysis for Promote the Brand Equity for an Enterprises to Sponsor the 2012 UEFA European Championship
}

\author{
Bin Gui ${ }^{\text {a }}$, and Zhanji Gui ${ }^{b^{*}}$
}

${ }^{a}$ School of Humanity and Law, Beijing University of Civil Engineering and Architecture, China

${ }^{\mathrm{b}}$ Department of Software Engineering, Hainan College of Software Technology, China

*Corresponding author: Zhanji Gui, gui6699@aliyun.com

\begin{abstract}
The research design used was both qualitative and quantitative. The sample size determined was 450; these included undergraduates, graduates, and newly employed personnel who had a brand sense. Simple random technique was used in the administering of the questionnaire. Descriptive and inferential statistics were applied in analysing the data to help in finding out the effect of sports sponsorship on a company's brand equity. The expected outcome from the study included identifying the effects that sports sponsorship has on brand equity.
\end{abstract}

Keywords: sports sponsorship, brand equity, statistics, consumers

\section{Introduction}

European football championship is an event that is held every four years, and involves 16 European teams that have qualified for the competition. Ukraine and Poland were chosen to be the venues for the Euro 2012 competition, and this provides an opportunity for companies to showcase their products. Sport sponsorship has become a vital part of football, and many changes have been seen in the way football is managed after sports sponsorship, by major corporations, and enterprises, came into the picture. Football events and competitions like the European football championship have experienced major growths in part due to the big funding from sponsors. The sponsors have grown to play a very vital role. Enterprises that get an opportunity to sponsor the Euro 2012 championship gain a lot from the worldwide televised event. The Euro 2012 which is a European only event attracts a major viewership all over the world, and the 23-day event provides a major platform for companies to popularize their brands. By a company associating itself with a major event like the Euro 2012, it is an opportunity to endear itself to the consumers, and helps it increase its customer base. Football is a world recognized, and played event which has found its way into many people's hearts, and minds. As the importance of sports sponsorship has grown, it has attracted many enterprises and companies to be part of football. The funds that corporations, and enterprises contribute in order to support football teams and competitions are very large. This is in line with the fact that an event like the Euro 2012 competition enables business enterprises to reach very many people around the world. Sports sponsorship has seen many products become brand equities through the association between companies, and sports. Sports sponsorship entails different forms; these are event sponsorship, team sponsorship, and individual sportsman sponsorship. Most business enterprises view it as an investment to sponsor major sports events like the Euro 2012; the returns they get from this endeavor are substantial. Being an official sponsor for Euro 2012 requires a huge amount of funds; it is expected to bring in big returns like increased stock returns, huge profits, and favorable advertising effect.

Sports marketing is an important aspect that should be undertaken by large business organizations especially those seeking international expansion. In some cases, organizations may lack the management skills that may lead to effective counter measures of promoting brand equity [1]. Experts can be hired in such cases to provide professional information on how strategies can be developed to promote brand value. The literature review looks into the empirical studies that have been conducted in the past to identify the 
ways in which an organization can offer countermeasures to existing pressures in order to promote its brand value by sponsoring the 2012 European Cup Games.

From the perspective of literature review on brand equity, a large number of researches locate the research on the dimensions as brand awareness, perceptive quality, brand image, brand association, Brand loyalty and brand identity, etc. (see [2]-[5]).

The research was conducted by sending questionnaires to specific people in two parts of the country namely the cities of London, and Bournemouth. The respondents were 450 people, they comprised of graduates, and undergraduates from diversified universities, and white collars who have just steeped into working positions. The response rate was $450 / 495$, giving $90.9 \%$ of the expected sample size.

The primary research was in the form of questions that were created in order to show the effect of sports marketing on a business enterprises' brand equity. The questions were designed in regard to the research questions, and the broad, and specific objectives that were set in the preceding chapters. The following content has shown the specific responses that were provided to the specific relevant questions, and just below the responses are short explanations that analyze the results received.

\section{Results and Interpretation of the Questionnaires}

\subsection{The composition of the sample (Quest- ions 11-13)}

- Gender: $58.7 \%$ of the respondents were male while $41.3 \%$ of the respondents were females.

- Level of Educatiod: $33.6 \%$ of the respondents had a college level of education, while $28.4 \%$ had an undergraduate level of education. $27.8 \%$ of the respondents had a postgraduate and above level of education. Respondents who achieved a high school or lower level of education were $10.2 \%$.

- Occupation: $62.7 \%$ of the respondents were students, $22.9 \%$ were teachers, and $4.4 \%$ were scientific and technical workers. $3.8 \%$ of the respondents were white collars, and $3.8 \%$ of the respondents were self-employed. $2.4 \%$ of the respondents were involved in other activities as their occupation.

\subsection{Effects of 2012 Euro-Cup corporate sponsorship (Questions 1)}

The first question in the questionnaire is a multiple choice question. All brands of title sponsors of 2012 European Cup are used as selected items.

Table 1 -Sponsorship Effects of Different Sponsors

\begin{tabular}{|c|c|c|c|c|}
\hline & & F & P & C P \\
\hline \multirow{7}{*}{ Valid } & Choose one in seven brand & 1 & 2 & 2 \\
\cline { 2 - 5 } & Choose two in seven brand & 173 & 38.4 & 38.7 \\
\cline { 2 - 5 } & Choose three in seven brand & 140 & 31.1 & 69.8 \\
\cline { 2 - 5 } & Choose four in seven brand & 70 & 15.6 & 85.3 \\
\cline { 2 - 5 } & Choose five in seven brand & 36 & 8.0 & 93.3 \\
\cline { 2 - 5 } & Choose six in seven brand & 30 & 6.7 & 100.0 \\
\cline { 2 - 5 } & Total & 450 & 100.0 & \\
\hline
\end{tabular}

Where $\mathrm{F}=$ "Frequency", $\mathrm{P}=$ "Percent”, $\mathrm{CP}=$ "Cumulative Percent "

Table 1 shows the preliminary statistical result of 450 questionnaires. It is shown in Table I that only one respondent knows only one brand of the seven title sponsors in 2012 European Cup, 173 respondents know two brands, 140 respondents know three brands, 70 respondents know four brands, 36 respondents know five brands, 30 respondents know six brands and 1 respondent knows all seven brands.

\subsection{Frequency of Purchase of Adidas Brand (Question 2)}

The respondents who stated they purchased Adidas products less than once a year were $34.2 \%$. 26.4\% of the respondents stated that they have never bought Adidas product, while $21.8 \%$ stated that they 
bought Adidas products once a year. The respondents who stated that they bought Adidas product more than once a year were $17.6 \%$.

\subsection{Results of questions 3-10 in the questionnaire}

In the questionnaire, results of questions 3-10 listed in Table 2 and 3

Table 2 -Results of Questions 3, 4, 8, 10

\begin{tabular}{|c|c|c|c|c|c|}
\hline & \multicolumn{4}{|c|}{ Valid } \\
\hline & & 1 & 2 & 3 & Total \\
\hline \multirow{2}{*}{ Q3 } & $\mathrm{F}$ & 118 & 94 & 238 & 450 \\
\hline & $\overline{\mathrm{P}}$ & 26.2 & 20.9 & 52.9 & 100.0 \\
\hline \multirow{2}{*}{ Q4 } & $\mathrm{F}$ & 143 & 107 & 200 & 450 \\
\hline & $\overline{\mathrm{P}}$ & 31.8 & 23.8 & 44.4 & 100.0 \\
\hline \multirow{2}{*}{ Q8 } & $\mathrm{F}$ & 126 & 86 & 238 & 450 \\
\hline & $\mathrm{P}$ & 28.0 & 19.1 & 52.9 & 100.0 \\
\hline \multirow{2}{*}{ Q10 } & $\mathrm{F}$ & 136 & 100 & 214 & 450 \\
\hline & $\mathrm{P}$ & 30.2 & 22.2 & 47.6 & 100.0 \\
\hline
\end{tabular}

1=“No", 2= " Don't Know ", 3= "Yes”, F= "Frequency ”, P="Percent”, CP=“Cumulative Percent ”.

Table 3 -Results of Questions 5, 6, 7, 9

\begin{tabular}{|c|c|c|c|c|c|c|c|}
\hline \multicolumn{2}{|c|}{} & & & \multicolumn{4}{c|}{ Valid } \\
\cline { 3 - 8 } \multicolumn{2}{c|}{} & 1 & 2 & 3 & 4 & 5 & Total \\
\hline \multirow{2}{*}{ Q5 } & $\mathrm{F}$ & 10 & 36 & 122 & 184 & 98 & 450 \\
\cline { 2 - 8 } & $\mathrm{P}$ & 2.2 & 8.0 & 27.1 & 40.9 & 21.8 & 100. \\
\hline \multirow{2}{*}{ Q6 } & $\mathrm{F}$ & 15 & 46 & 110 & 177 & 102 & 450 \\
\cline { 2 - 8 } & $\mathrm{P}$ & 3.2 & 10.2 & 24.4 & 39.3 & 22.9 & 100. \\
\hline \multirow{2}{*}{ Q7 } & $\mathrm{F}$ & 19 & 37 & 122 & 173 & 99 & 450 \\
\cline { 2 - 8 } & $\mathrm{P}$ & 4.2 & 8.2 & 27.1 & 38.4 & 22.0 & 100. \\
\hline \multirow{2}{*}{ Q9 } & $\mathrm{F}$ & 19 & 39 & 114 & 160 & 118 & 450 \\
\cline { 2 - 8 } & $\mathrm{P}$ & 4.2 & 8.7 & 25.3 & 36.6 & 26.2 & 100. \\
\hline
\end{tabular}

1 = "Strongly disagree ", 2 = "disagree ", 3 = "Neither agree nor disagree",4= "agree ", $5=$ "Strongly agree ", $\mathrm{F}=$

"Frequency ”, $\mathrm{P}=$ ="Percent”, $\mathrm{CP}=$ "“Cumulative Percent”.

\section{Reliability and Validity Questionnaire Scale}

Reliability Analysis Reliability refers to the degree of consistency of results in repeated measure of the same thing. It reflects the stability or reliability of the measuring tool. Here, it mainly refers to the analysis on the internal reliability of questionnaire scale. Cronbach's Alpha coefficient method is the most commonly used method for measuring the internal reliability. Higher a value means a higher degree of conformity between each item of the variable, i.e. a higher degree of internal consistency. It is suitable for conducting reliability analysis specific to the questionnaire scale. The following reference range of reliability is summarized according to the research report related to reliability, as shown in Table 4.

Table 4 -The Referce Range of Scale Reliability

\begin{tabular}{|c|c|}
\hline Range of Cronbach 's $\alpha$ & Reliability \\
\hline Cronbach 's $\alpha \leq 0.6$ & Very unreliability \\
\hline $0.60<$ Cronbach's $\alpha \leq 0.65$ & Unreliability \\
\hline $0.65<$ Cronbach's $\alpha \leq 0.70$ & $\begin{array}{c}\text { Minimum acceptable } \\
\text { value of reliability }\end{array}$ \\
\hline $0.70<$ Cronbach 's $\alpha \leq 0.80$ & Reliability \\
\hline $0.80<$ Cronbach 's $\alpha \leq 0.90$ & Very reliability \\
\hline $0.90<$ Cronbach 's $\alpha$ & Completely reliability \\
\hline
\end{tabular}


The selection mode of menu Analyze-Scale-Reliability Analysis in SPSS 20.0 statistical package used in this research is Alpha. Table 5 shows the value of Cronbach $\alpha$ after reliability analysis on each measurement factor of dependent variables and independent variables. Here, Reliability of Questions 1-10 of the questionnaire is analyzed, and basic Questions 11 to 13 does not need reliability analysis.

Table 5 -Reliability Statistics

\begin{tabular}{|c|c|c|}
\hline Cronbach's $\alpha$ & Cronbach's $\alpha$ Based on Standardized Items & N of Items \\
\hline .695 & .709 & 10 \\
\hline
\end{tabular}

\subsection{Validity Analysis}

Validity refers to the degree to which the measuring tool or means can measure the object accurately, i.e. effect- iveness.

Before conducting factor analysis, we should first use Bartlett's-test and KMO (Kaiser-Meyer-Olkin measure of sampling) numerical values to inspect its conformity and determine whether the observed value of each variable is suitable for factor analysis. When $\mathrm{P}$ value of Bartlett's-test approaches 0 , it means the factor analysis can be further conducted. KMO is the measurement of sampling adequacy (its value is between 0 and 1). When KMO value becomes higher (approaching 1 ), there will be more common factors among modify addresses, the net correlation coefficient among variables will be lower and it will be more suitable for factor analysis. According to the scholar Kaiser (1974), if KMO value is less than 0.5 , it is not suitable for factor analysis. The mediocre standard for factor analysis is at least above 0.6. KMO value here is 0.793. It means common factors exist among variables and variables are suitable for factor analysis.

Table 6 shows the factor matrix after rotation. Orthogonal rotation is conducted using Varimax. It can be found from the component matrix after rotation that common factor I includes Q3, Q4, Q8 and Q10; common factor II includes Q5, Q6, Q7 and Q9; and common factor III includes Q2, we can consider deleting the item Q2(Each factors should have at least two item). Common factor I includesQ10, Q8, Q3 and Q4 which contain relevant concepts of sports sponsorship marketing and common factor II includes Q7, Q6, Q9 and Q5 which contain relevant concepts of brand equity. Through statistic analysis, the factor-loading coefficient of each dimensionality item is above 0.6 , which shows that the scale designed in this paper has good validity.

Table 6 -Rotated Component Matrixa

\begin{tabular}{|c|c|c|c|}
\hline \multirow{2}{*}{} & \multicolumn{3}{|c|}{ Component } \\
\cline { 2 - 4 } & 1 & 2 & 3 \\
\hline Q8 & .762 & .133 & .123 \\
\hline Q10 & .761 & .146 & -.041 \\
\hline Q3 & .707 & .122 & -.180 \\
\hline Q4 & .673 & .149 & .042 \\
\hline Q7 & .112 & .787 & .005 \\
\hline Q6 & .230 & .677 & .089 \\
\hline Q9 & .260 & .660 & .039 \\
\hline Q5 & .000 & .657 & -.161 \\
\hline Q2 & -.030 & -.024 & .970 \\
\hline
\end{tabular}

\section{Conclusions}

It is very important for companies to evaluate the value of their brand, and sponsorship complementarities in choosing the most fitting sports events. The main reason behind this line of thought is because the appropriate event provides the right channel of reaching the target population. The audiences targeted in most instances view the companies which sponsor sports events as the main characters just as those who are involved in the sports, for example, the football players. It is important for companies to understand the whole range of marketing strategies which are involved in sports 
sponsorship. The company's marketers should make a point of creating a bond with the sports event which it sponsors. Companies with less powerful brands may encounter hardships in sponsoring the major sports events. If the condition remains the same for both powerful and less powerful brands, powerful brand equity will not always lead to an increase in the value of the firm. Therefore, if a less popular company with low brand equity sponsors a sports event, this can lead to increased recall, and brand awareness.

Sports sponsorship is still an efficient and effective strategy of advertising which is applied in today's market. It has proven to be one of the most successful ways of building an emotional, and communication bond with consumers. Brand and event fit is one of the factors which mainly determine the impact on brand equity, and, therefore, the short term financial rewards. The association that exists between sports sponsorship and financial rewards is mainly determined by the fit between brand equity, and image. Companies should understand that factors like the period of the event; the type of sports; and the popularity have not yet been proven to dramatically affect the financial rewards. Business experts should study more on the effects of sports sponsorship on brand equity. This will allow the publication of more comprehensive results, which will allow companies to make informed choices before they make any steps in terms of sponsoring major sports events like the Euro 2012.

\section{Acknowlegments}

The research work was supported by National Natural Science Foundation of China (Grant No. 60963025) and Natural Science Foundation of Hainan Provincial (Grant No. 613166, 112008).

\section{References}

1 D.A. Aaker, Managing brand equity. The Free Press. New York, 1991

2 D.A. Aaker, and K.L. Keller, Consumer evaluations of brand extensions, Journal of Marketing. vol. 3, 1990, pp. 27-42

3 JL. Aaker, (1997). Dimensions of br and personality, Journal of Marketing Research, 1997, vol. 34, pp. 347-356.

4 B. Yoo, N. Donthu, \& S. Lee, An examination of selected marketing mix elements and brand equity, Journal of the academy of marketing science,2000, vol. 28, pp. 195-211.

5 K.L. Keller, Strategic brand management: Building, measuring, and managing brand equity. Upper Saddle River: Prentice Hall, 2003. 